\title{
Electron Beam Cold Hearth Melted Titanium Alloys and the Possibility of Their Use as Anti-Ballistic Materials
}

\author{
Markovsky P.E. ${ }^{1}$, Bondarchuk V.I. ${ }^{1}$, Akhonin S.V. ${ }^{2}$, Berezos A.V. ${ }^{2}$ \\ ${ }^{1}$ G.V. Kurdyumov Institute for Metal Physics of National Academy of Sciences of Ukraine, 36, Vernadsky Blvd., 03142, Kyiv, \\ Ukraine \\ ${ }^{2}$ E.O. Paton Electric Welding Institute of National Academy of Sciences of Ukraine, 12, Kazimir Malevich Str., 03150, Kyiv, \\ Ukraine
}

\begin{abstract}
Three commercial titanium alloys: two-phase $\alpha+\beta$ Ti-6Al-4V (low alloyed), and T110 (Ti-5.5Al-1.5V-1.5Mo-4Nb-0.5Fe, higheralloyed), and $\beta$-metastable Ti-1.5Al-6.8Mo-4.5Fe were melted using EBCHM approach in the form of $100 \mathrm{~mm}$ in diameter ingots with the weight of about $20 \mathrm{~kg}$ each. After $3 \mathrm{D}$ hot pressing at single $\beta$-field temperatures ingots were rolled at temperatures below $\beta$-transus onto plates with thickness varying from $3 \mathrm{~mm}$ to $25 \mathrm{~mm}$. Different heat treatments, including annealing at $\alpha+\beta$ or $\beta$ field temperatures, and special strengthening Surface Rapid Heat Treatment (SRHT) which after final aging provided special gradient microstructure with a hardened surface layer over ductile basic core, were employed. Mechanical properties were studied with tensile and 3-point flexure tests. It was established that the best combination of tensile strength and ductility in all alloys studied was obtained after SRHT, whereas at 3-point flexure better characteristics were obtained for the materials annealed at temperatures of $(\alpha+\beta)$-field. At the same time, ballistic tests made at a certified laboratory with different kinds of ammunition showed essential superiority of plates having upper layers strengthened with SRHT. The effect of microstructure of the alloys, plate thickness and type of used ammunition on ballistic resistance is discussed.
\end{abstract}

\section{Introduction}

The titanium alloys are a unique class of structural materials for many applications, especially aerospace and military, first of all, due to their high specific strength well-balanced with other mechanical and service properties [1-3]. As for military equipment, most titanium alloys are used in the manufacture of various types of armour [2-4]. At the same time, in addition to the requirements for suitable physical and mechanical properties, the requirement for maximum cost reduction is put to such armour materials. The latter requirement can be satisfied both by using the cheapest alloying elements on the melting of titanium alloys $[5,6]$ and by maximally simplifying the technology of smelting and subsequent thermomechanical and thermal treatments $[2,7]$. As it was shown in [2], single-melt Electron-Beam Cold Hearth Melting (EBCHM) approach in combination with direct rolling allows to essentially reduce costs of titanium plates (sheets) to be employed as armour material. The present work was devoted to the study of the influence of this technological approach on the mechanical properties and ballistic resistance of three titanium alloys: two-phase $\alpha+\beta$ Ti-6Al-4V (low alloyed), T110 (Ti-5.5Al-1.5V-1.5Mo-4Nb-0.5Fe, higher-alloyed), and $\beta$-metastable Ti1.5Al-6.8Mo-4.5Fe. Special attention was paid to the application of strengthening Surface Rapid Heat Treatment (SRHT) which allows to form gradient microstructural states uniting hardened surface layers with ductile core $[8,9]$.

\section{Materials and Experimental Procedure}

The above mentioned alloys were melted with $\mathrm{EBCH}$ melting approach as $100 \mathrm{~mm}$ diameter and about $200 \mathrm{~mm}$ long ingots, using titanium sponge and Al-V master alloy (for Ti-6-4) or pure $\mathrm{Al}, \mathrm{V}, \mathrm{Mo}, \mathrm{Nb}$, and $\mathrm{Fe}$ (T110), as well as pure $\mathrm{Al}$ and Fe-Mo master alloy (for Ti-1.5Al-6.8Mo-4.5Fe). The ingots were melted at laboratory scale electronic beam unit UE-208 [10] by single melting. Real chemical compositions of melted ingots (averaged for 3 different locations of ingots) were following: i) Ti5.8(wt.\%)Al-3.86V; ii) Ti-5,5Al-1,2V-1V-0,7Zr-3,8Nb-2Fe; and iii) Ti-1.6Al-6.3Mo-4.36Fe. All three ingots were subjected to turning, 3D hot pressing, rolling and several types of treatments ensuring the formation of different microstructural states - all details of these procedures were described in [9]. As a result, materials of several thicknesses (varying from 3 to $14.5 \mathrm{~mm}$ ) were obtained; their microstructure and mechanical properties were studied, and ballistic tests were performed using different weapons and ammunition at a certified laboratory of Ivan Tchernyakhovsky National University of Defense of Ukraine. The details of investigation and tests were also given in [9]. In the present study we used two types of bullets and ammunitions: the $\mathbf{1}^{\text {st }}$ type - 7.62 caliber bullets with "soft" (not-hardened) steel core, which impacted the target due to kinetic energy only. The bullets \#1 were launched from a handgun TT and had mass 5.5 grams, average speed $420 \pm 12 \mathrm{~m} / \mathrm{sec}$, and specific kinetic energy $10.5-12$ $\mathrm{J} / \mathrm{mm} 2$ (hereafter designated as TT); the bullets \#2 were launched from a machinegun and had mass 9.62 grams, average speed $819 \pm 15 \mathrm{~m} / \mathrm{sec}$, and specific kinetic energy $71-73 \mathrm{~J} / \mathrm{mm} 2$ (hereafter designated as LPS). The $\mathbf{2}^{\text {nd }}$ type bullets were launched from a machinegun and had $5.45 \mathrm{~mm}$ caliber with hardened steel core, average speed $915 \pm 18 \mathrm{~m} / \mathrm{sec}$, and specific kinetic energy $65-67$ $\mathrm{J} / \mathrm{mm} 2$ (hereafter designated as PP). 


\section{Results and Discussions}

Typical examples of microstructures of studied plates and sheets after different treatments are presented in Fig. 1. As-rolled conditions have pronounced laminated microstructure (Fig. 1a, d, g). Annealing at temperatures of two-phase $\alpha+\beta$ field $(880 \mathrm{oC}$ for Ti-6-4 and T110, and 750oC for Ti-1.6Al-6.3Mo-4.36Fe) formed microstructures in which intragrain $\alpha$ - particles are partially globularized (Fig. 1b, e, h). Application of SRHT to all three alloys after annealing formed gradient microstructural state in which

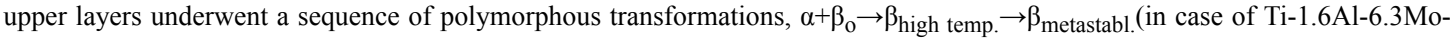
$4.36 \mathrm{Fe}$ ) or $\alpha+\beta \mathrm{o} \rightarrow \beta$ high temp. $\rightarrow \beta+\alpha^{\prime}\left(\alpha^{\prime \prime}\right)$ (in case of Ti-5-4 and T110), and after final aging hardened stable $\alpha+\beta$ state was formed in the surface layers (Fig. 1c, $\mathrm{f}, \mathrm{i}$ ).

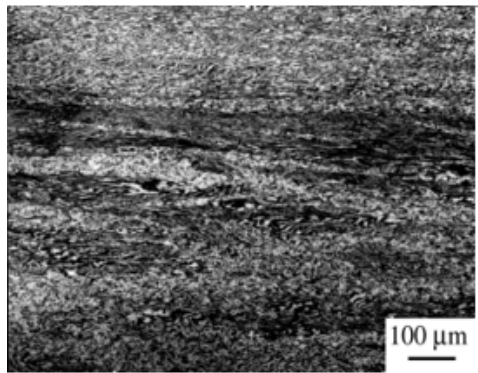

1

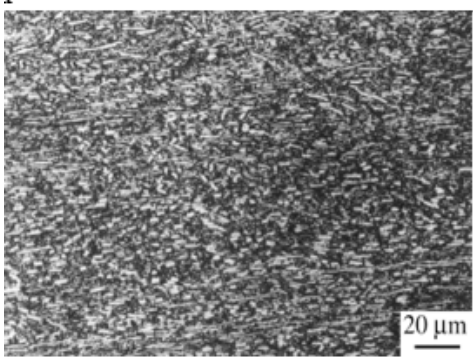

$\mathrm{b}$

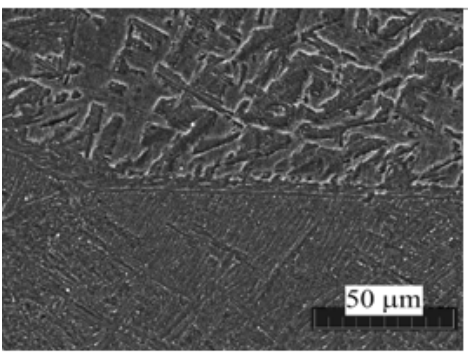

c

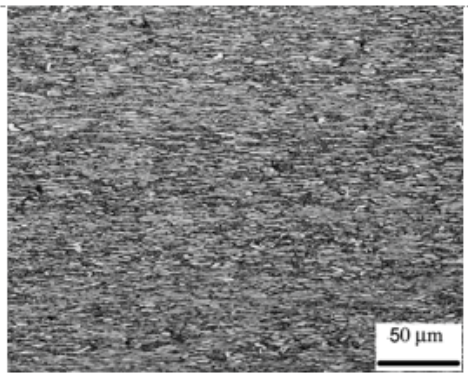

\section{d}

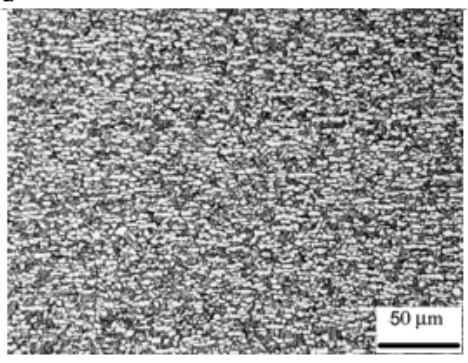

e

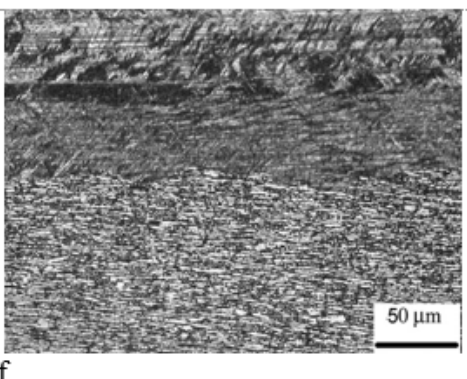

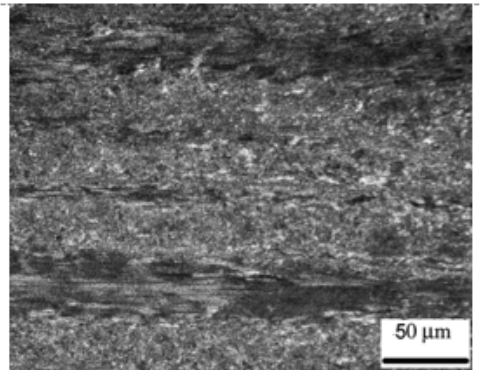

g
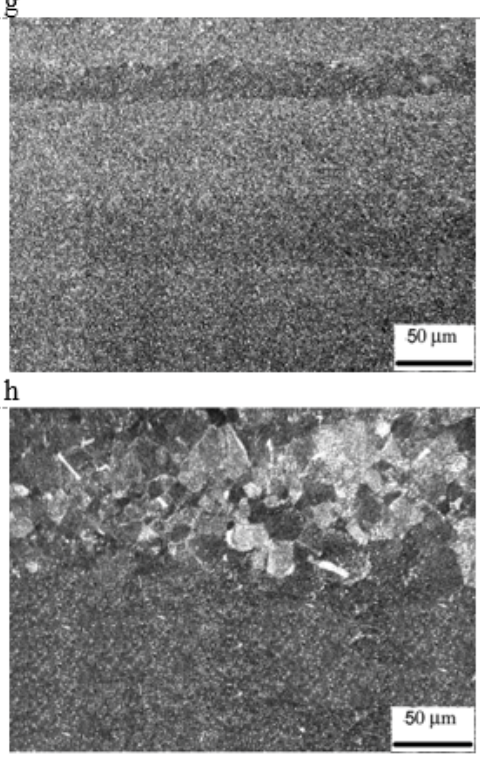

Fig. 1 The microstructure of titanium alloys Ti-6-4 (a-c), T110 (d-f), and Ti-1.5Al-6.8Mo-4.5Fe (g-i) in the states: (a, d, g) after rolling, (b, e, h) after annealing at temperatures of $\alpha+\beta$ field, (c, f, i) after SRHT. (a-h, f, i) OM, (c) SEM.

Mechanical properties of studied alloys in different microstructural states are listed in Table 1. First of all it is necessary to mention that annealing in all cases decreased tensile strength and increased ductility as a result of residual stress relaxation and stabilization of the phase composition, while subsequent SRHT caused essential increase in general strength, which is more noticeable for more alloyed T110 and Ti-1.5Al-6.8Mo-4.5Fe alloys where high UTS is accompanied by rather a good ductility.

Another situation was observed for 3-point flexure tests which, as it was mentioned in [7, 11], resemble ballistic tests by the scheme of the external force application. In this case the highest levels of strength were also observed for the strengthened by 
SRHT T110 and Ti-1.5Al-6.8Mo-4.5Fe alloys; however, the last alloy showed rather low and poorly reproducible ductility. At the same time, Ti-6-4 alloy showed a better balance of properties in the as-annealed state as compared with SRHT one.

The decisive influence of microstructure type on the ballistic behavior of titanium alloys very clearly can be illustrated with cross-sections of channels perforated in $4 \mathrm{~mm}$ thick T110 sheets shot through by LPS bullets of 7.62 caliber with "soft" steel core (bullet of the 1st type in [9], which impacted the target due to kinetic energy only), mass 9.62 grams, average speed $915 \pm 18$ $\mathrm{m} / \mathrm{sec}$, and specific kinetic energy $65 \pm 4 \mathrm{~J} / \mathrm{mm} 2$ (Fig. 2). It is clearly seen that as-rolled material underwent ductile deformation, and delamination took place along the boundaries of non-recrystallized and elongated in the rolling direction $\beta$-grains (Fig. 2a). The annealed state was perforated in a fully ductile manner despite the fact that grains were not recrystallized, and the structure of primary $\beta$-grains had no effect, obviously, because the ductility of material noticeably increased (Fig. $2 b$ ). Strengthened by SRHT sheet showed delamination as well, but the fracture was absolutely brittle, obviously due to the fact that the balance between strength and ductility strongly biased towards strength (Fig. 2c).

Table 1

Typical mechanical properties of investigated alloys $(10 \mathrm{~mm}$ thick plates) after different heat treatments.

\begin{tabular}{|c|c|c|c|c|c|c|c|c|}
\hline \multirow[t]{2}{*}{ \#\# } & \multirow[t]{2}{*}{ Structural State } & \multicolumn{4}{|c|}{ Tensile properties* } & \multicolumn{3}{|c|}{ Flexure properties** } \\
\hline & & $\mathrm{YS}, \mathrm{MPa}$ & $\begin{array}{l}\text { UTS, } \\
\mathrm{MPa}\end{array}$ & $\mathrm{E} 1, \%$ & $\mathrm{RA}, \%$ & $\mathrm{YS}, \mathrm{MPa}$ & $\mathrm{FS}, \mathrm{MPa}$ & FSt, \% \\
\hline \multicolumn{9}{|c|}{ Ti-6-4 } \\
\hline 1 & As-rolled & 991 & 1021 & 6.54 & 30.2 & 1808 & 1936 & 8.2 \\
\hline 2 & Annealed $880^{\circ} \mathrm{C}, 2 \mathrm{~h}$ & 910 & 965 & 12.65 & 47.51 & 1634 & 2094 & $>24$ \\
\hline 3 & $\begin{array}{c}\text { Annealed } 880^{\circ} \mathrm{C}, 2 \mathrm{~h}+\text { SRHT } \\
+550^{\circ} \mathrm{C}, 6 \mathrm{~h} .\end{array}$ & 1260 & 1295 & 7.91 & 32.4 & 1726 & 1986 & 16.2 \\
\hline \multicolumn{9}{|c|}{ ( } \\
\hline 4 & As-rolled & 1040 & 1104 & 14.10 & 33.27 & 1620 & 2350 & 11.28 \\
\hline 5 & Annealed $880^{\circ} \mathrm{C}, 2 \mathrm{~h}$ & 980 & 995 & 16.20 & 42.61 & 1638 & 2037 & 9.71 \\
\hline 6 & $\begin{array}{c}\text { Annealed } 880^{\circ} \mathrm{C}, 2 \mathrm{~h}+\mathrm{SRHT} \\
+550^{\circ} \mathrm{C}, 6 \mathrm{~h} .\end{array}$ & 1389 & 1420 & 8.22 & 34.21 & 1678 & 2156 & 13.58 \\
\hline \multicolumn{9}{|c|}{ Ti-1.5Al-6.8Mo-4.5Fe } \\
\hline 7 & As-rolled & 1160 & 1165 & 8.69 & 23.11 & 1887 & 1887 & - \\
\hline 8 & Annealed $750^{\circ} \mathrm{C}, 2 \mathrm{~h}$ & 1089 & 1090 & 15.22 & 46.50 & 1785 & 2068 & 11.2 \\
\hline 9 & $\begin{array}{l}\text { Annealed } 750^{\circ} \mathrm{C}, 2 \mathrm{~h}+\mathrm{SRHT} \\
+550^{\circ} \mathrm{C}, 6 \text { год. }\end{array}$ & 1427 & 1465 & 7.2 & 19.55 & 1912 & 1994 & 2.8 \\
\hline
\end{tabular}

*YS - yield stress; UTS - ultimate tensile stress; El - elongation; RA - reduction in area.

**YS - yield stress; FS - flexure stress; FSt - flexure strain. 


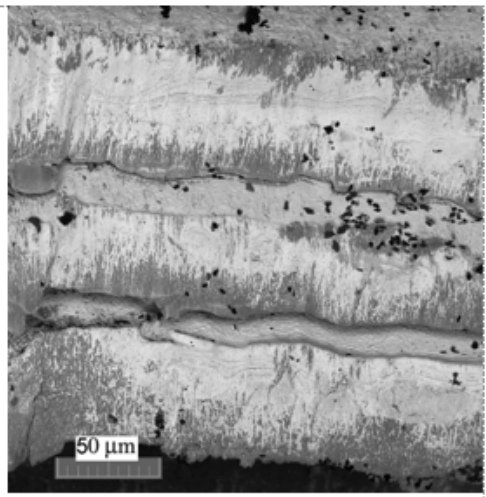

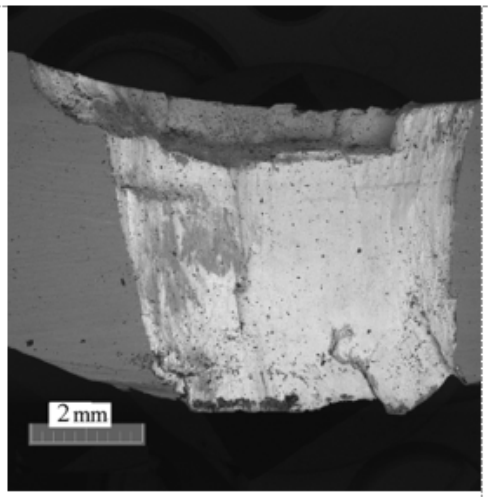

b

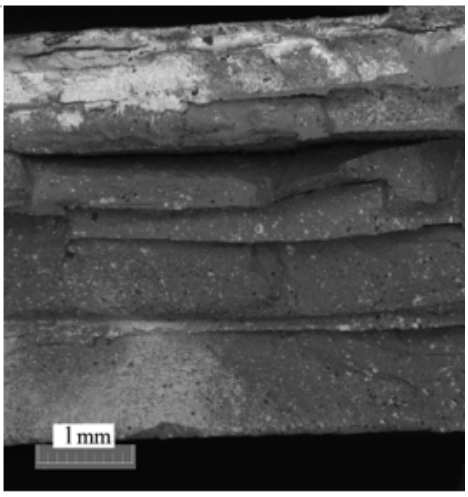

Fig. 2. General views of pierced channels in T110 alloy sheets of $4.5 \mathrm{~mm}$ thickness after testing by the 1 st type bullets. States: (a) - after rolling, (b) - annealed, (c) - after SRHT. SEM.

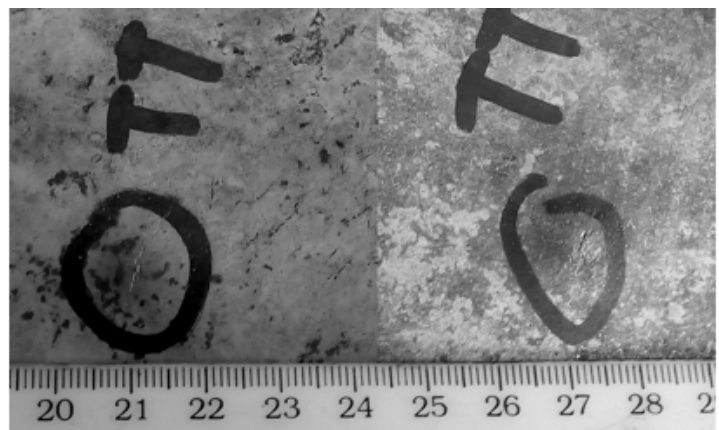

a

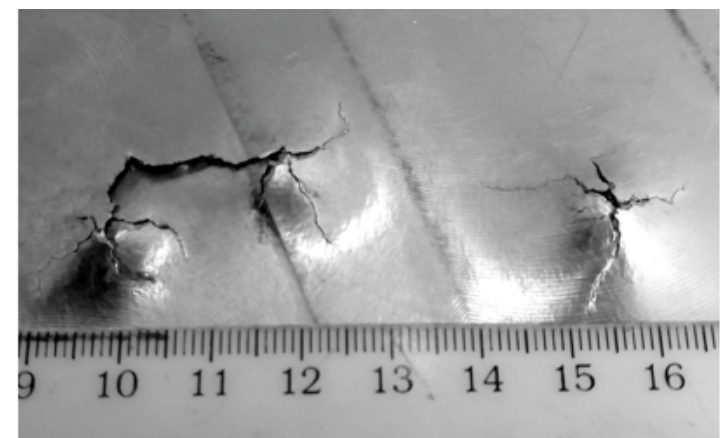

b

Fig. 3. Comparison of annealed $3.1 \mathrm{~mm}$ thick sheets of (a) T100 and (b) Ti-6-4 after ballistic tests with TT bullets; back side views.

Fig. 3 illustrates the difference in ballistic resistance of $3 \mathrm{~mm}$ thick sheets made of T110 and widely used Ti-6-4 alloys after the same annealing shot by 1 st type TT bullets with the specific kinetic energy of about $11 \mathrm{~J} / \mathrm{mm}^{2}$. It is clearly seen that both materials were not pierced; however, in the T110 only small bulges appeared, and through-thickness cracks were not observed, whereas in Ti-6-4 the bulges were bigger, and the material almost completely cracked.

Ballistic tests of thicker plates with more powerful ammunition of both types, namely LPS (1st type) and PP (2nd type), also showed essential sensitivity to the alloy composition and microstructural state. It is important to underline that all $7 \mathrm{~mm}$ thick plates of Ti-6-4 with various microstructures (see Fig. 1a-1c) were perforated by both LPS and PP bullets, whereas T100 plates of the same thickness were pierced by PP bullets in the as-rolled state only. The last effect can be explained by a significant difference in hardness of T100 hardened surface (about 350-380 MPa) and hardened steel core of PP bullets (above $700 \mathrm{MPa}$ ). Thicker $(10 \mathrm{~mm})$ plates of both alloys were not pierced; however, the damage caused by bullets (post-penetration effect) was much worse in Ti-6-4 than in T110. When testing thicker $(14.5 \mathrm{~mm})$ plates, the result was almost the same in all cases (compositions and microstructural states).

Ballistic tests of Ti-1.5Al-6.8Mo-4.5Fe alloy showed the worst results among all alloys tested - only $14.5 \mathrm{~mm}$ thick plate withstood the tests by those bullets which did not perforate other two alloys with a thickness of $10 \mathrm{~mm}$. This result was somewhat unexpected, since the standard tensile and 3-point flexure properties (pp. 7-8 in Table 1) of Ti-1.5Al-6.8Mo-4.5Fe alloy look rather good, and earlier it was possible to obtain a very high balance of mechanical (tensile) properties on rods of this alloy after special thermomechanical processing followed by controlled recrystallization [12]. Obviously, this negative result may be 
explained by the fact that Ti-1.5Al-6.8Mo-4.5Fe alloy after such a relatively simple thermomechanical processing had a significant structural heterogeneity, namely laminations, which had a negative effect on properties [13], as well as finer $\alpha$-phase microstructure (for instance, compare Figs $1 \mathrm{~h}$ with 1e). It should also be noted that after shooting by 2-3 bullets without serious damage, the hardened plates of this alloy collapsed in unexpected places at the next bullet hit, which can be explained by the complicated nature of appeared stresses accommodation.

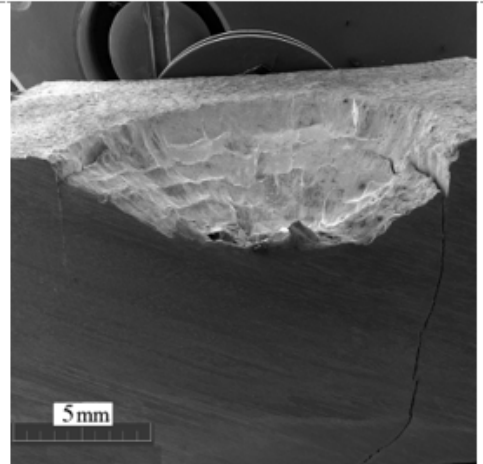

a

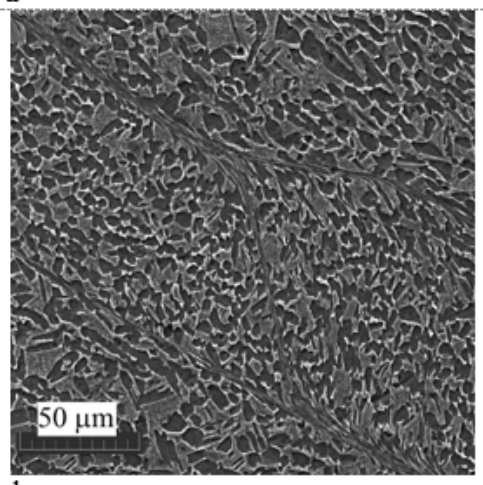

d

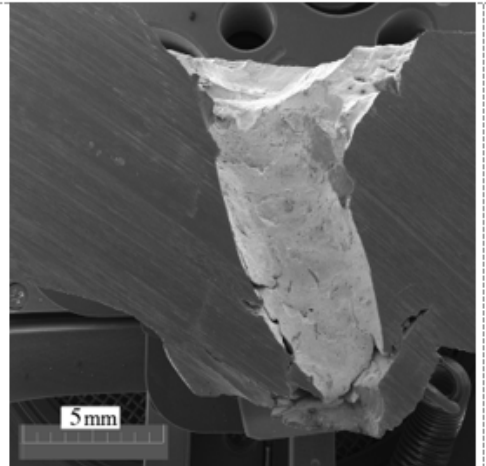

$\mathrm{b}$

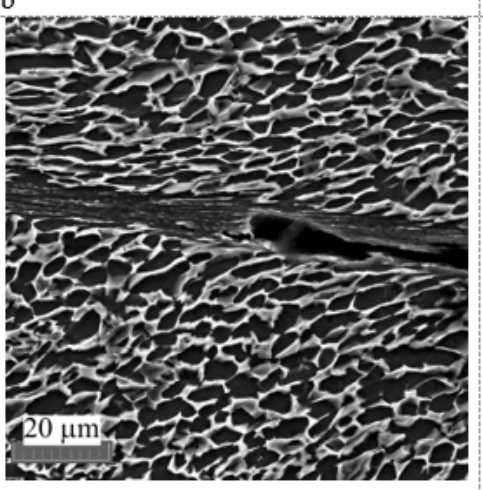

e
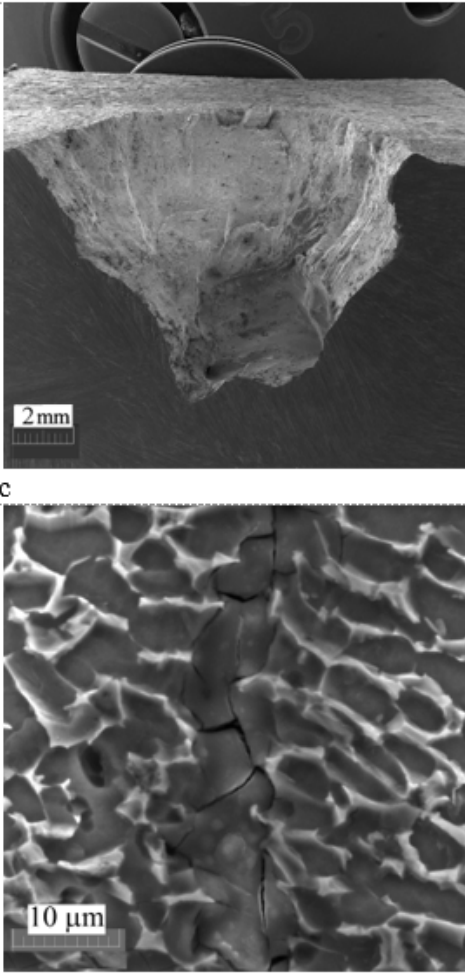

f

Fig. 4. General views of the damaged zone (a-c), and microstructure around it (d-f) of the T110 alloy tested with bullets of the 1 st type (LPS, a, d), and bullets of the 2 nd type (PP, d, c, e, f). (a, d) plate $10 \mathrm{~mm}$ thick annealed $880^{\circ} \mathrm{C}, 1.5 \mathrm{hours},(\mathrm{b}, \mathrm{e})$ in a state after rolling, $(c, f)$ after annealing of $880^{\circ} \mathrm{C}, 1.5$ hours and SRHT. SEM.

The influence of microstructure on ballistic resistance can be clearly illustrated on the example of T110 alloy, $10 \mathrm{~mm}$ thick plates (Fig. 4). "Soft" core 1st type (which had approximately the same hardness as T100 alloy - about 350 MPa by the Brinell scale) LPS bullets made just a surface crater about $4 \mathrm{~mm}$ deep (Fig. 4a); the outgoing from crater into depth cracks had length of a few millimeters and were surrounded by Adiabatic Shear Bands (ASB, Fig. 4d). The 2nd type PP bullets (their core hardness exceeded the hardness of titanium alloys at least by 2 times) in addition to the surface crater left deep channels in the plates of both as-rolled and annealed material (Fig. 4b); some ASBs transformed into cracks (Fig. 4e). The plates with hardened by SRHT surface had surface craters of approximately the same size; however, the channels left by hard bullet cores deviated at larger angles and had a much shorter length (Fig. 4c), that indicates a greater absorption and/or dispersion of the bullet energy by the surface layer. Microcracks in the bands similar to ASB are observed around the channel, but they have a serrated shape that makes unclear physical nature of these bands (Fig. 4f).

A comparison of different alloys can be made using approach based on the employment of such independent and generalizing parameter as the specific kinetic energy of bullets [9]. All three studied alloys are compared in coordinates "specific kinetic energy - thickness of plates" on the example of ballistic tests with bullets of the 1st type (TT and LPS with "soft" steel core) in 
Fig. 5a. This presentation of obtained results illustrates that in areas to the left of each straight line ((1) - T110, (2) - Ti-6-4, and (3) - Ti-1.5Al-6.8Mo-4.5Fe) sheets and plates of a given thickness are able to withstand the test by this type bullets with a given kinetic energy, whereas on the right from the lines the materials can be perforated. Therefore, a simple comparison of these results allows to conclude that T100 alloy has visible superiority over two others, and Ti-1.5Al-6.8Mo-4.5Fe is worth one. The last conclusion was also made by J. Fanning for strengthened state via conventional solid solution and aging heat treatment for TIMETAL-LCB alloy [3]; however, we think that this alloy still has some potential, and development of better thermomechanical processing is required to discover it.
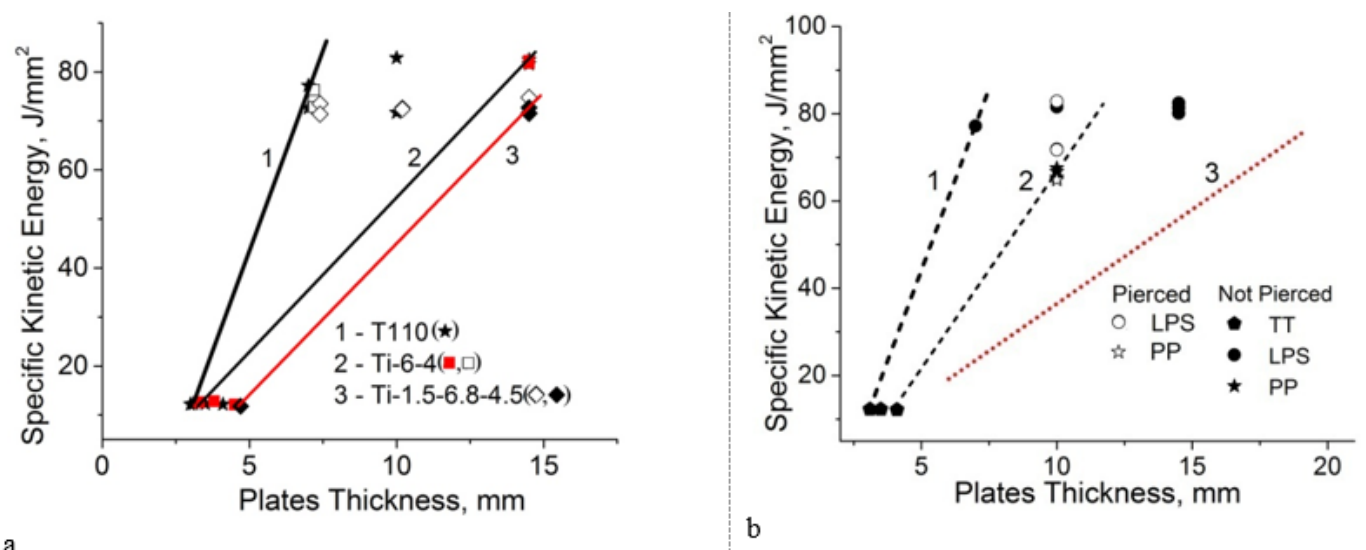

Fig. 5. Dependencies between specific kinetic energy of bullets and thickness of tested plates. (a) - testing by bullets of the 1st type of different alloys: (1) - T110, (2) - Ti-6-4, (3) - Ti-1.5Al-6.8Mo-4.5Fe. (b) - testing of T110 in the state after SRHT by bullets of (1) - 1st type with not hardened steel core, (2) - 2nd type with steel core hardened above $700 \mathrm{HV}$. (3) the dependence obtained for Ti-6-4 alloy tested with $7.62 \mathrm{~mm}$ caliber bullets with soft steel cores [3, 4]. Open symbols perforated, close symbols - not perforated.

The potential of T110 alloy illustrates Fig. 5b which represents the best results of tests with bullets of two types for plates with different thicknesses in one state with gradient microstructure obtained by SRHT. Comparison of lines (1) and (2) shows the influence of the difference in hardness between the core of bullets and tested plates. For example, when material was tested by bullets with "soft" core (line 1) and specific kinetic energy of about $80 \mathrm{~J} / \mathrm{mm} 2$, only $7 \mathrm{~mm}$ thick plates withstood it; however, if core is at least twice harder than tested plate (line 2), bullets will not perforate plates thicker than $10 \mathrm{~mm}$. So, the distance between lines (1) and (2) illustrates exactly the effect of steel core hardness. It is also interesting to compare our results with the data of detailed study performed by J. Fanning [3,4] - the difference between lines (1) and (3) shows the superiority of T110 plates and used SRHT hardening over Ti-6-4 with standard (not specified) structural conditions.

\section{Conclusions}

1. Tree different alloys, T-6Al-4V, T110 (Ti-5.5Al-1.5V-1.5Mo-4Nb-0.5Fe), and Ti-1.5Al-6.8Mo-4.5Fe, were melted with electron beam cold hearth method and hot rolled into plates/sheets of different thickness, then they were subjected to several heat treatments and ballistic tests using real weapons and ammunitions.

2. It is shown that the best balance of mechanical properties and ballistic resistance was provided by plates with special gradient microstructural states formed by Surface Rapid Heat Treatment.

3. T110 (Ti-5.5Al-1.5V-1.5Mo-4Nb-0.5Fe) alloy has the best ballistic resistance in comparison with two other alloys when tested by both type of bullets - with "soft" (not strengthened), as well as "hard" (thermally strengthened) steel cores.

\section{Acknowledgment}

Parts of present work were supported by National Academy of Sciences of Ukraine funding within the project IMF-2017-1, and by NATO Science for Peace and Security program (project G5030).

\section{References}

1. G. Luetjering, and J.C. Williams, Titanium, Springer-Verlag (Berlin) (Second Edition) (2007).

2. J.S. Montgomery, M.G.Y. Wells, Titanium armor applications in combat vehicles, JOM (2001), vol. 4, p.29.

3. J. Fanning, Military Application for $\beta$ Titanium Alloys, JMEP (2005), vol. 14, p. 686.

4. J. Fanning (2007) Ballistic Evaluation of Titanium Alloys against Handgun Ammunition (In Ti-2007 Science and 
Technology, Proceedings of the 11th World Conference on Titanium) (3-7 June, Kyoto, Japan, The Japan Institute of Metals) p. 487.

5. D. Eylon, Beta-titanium alloys - an Overview //3rd Japan International SAMPE Symposium. Tokyo, 1993. 1588-1595.

6. M. Ikeda, S. Komatsu, K. Inoue, H. Shiota, and T. Imose, Microstructure and tensile properties of Ti-Fe-Cr alloys, // Mat. Sci., and Technology, June 2000, v. 16, pp. 605-608.

7. Markovsky P.E., Ivasishin O.M., et. al., Effect of Microstructure, Deformation Mode and Rate on Mechanical Behavior of Electron-Beam Melted Ti-6Al-4V and Ti-1.5Al-6.8Mo-4.5Fe Alloys, Progress in Physics of Metals, 2018, vol. 19, pp. 309336.

8. Markovsky P.E., Application of Local Rapid Heat Treatment for Improvement of Microstructure and Mechanical Properties of Titanium Products, Key Engineering Materials, 2010, v. 436, pp.185-194.

9. Ivasishin O.M., Markovsky P.E., et. al., Microstructure and Properties of titanium-based materials perspective for antiballistic protection, Progress in Physics of Metals, 2019, \#2, in press.

10. Akhonin S.V., Berezos V.A., et. al., Electron-beam melting of a new high-strength titanium alloy T120, (in Ukrainian), Modern Electrometallurgy (2017), №1, p.10.

11. Markovsky P.E. Mechanical Behavior of Titanium Alloys under Different Conditions of Loading, Material Science Forum, vol.941, THERMEC-2018, pp. 839-844.

12. Ivasishin O.M., Markovsky P.E., et. al., A Comparative Study of the Mechanical Properties of High-Strength Beta-Titanium Alloys, Journal of Alloys and Compounds, 2008, Volume 457, Issues 1-2, p. 296-309

13. Markovsky P.E., Akhonin S.V., et. al., Production of high-strength titanium alloy Ti-1.5Al-6.8Mo-4.555Fe by EBCHM method (in Russian), Special Electrometallurgy, 2018, 5, №1, c. 9-16. 